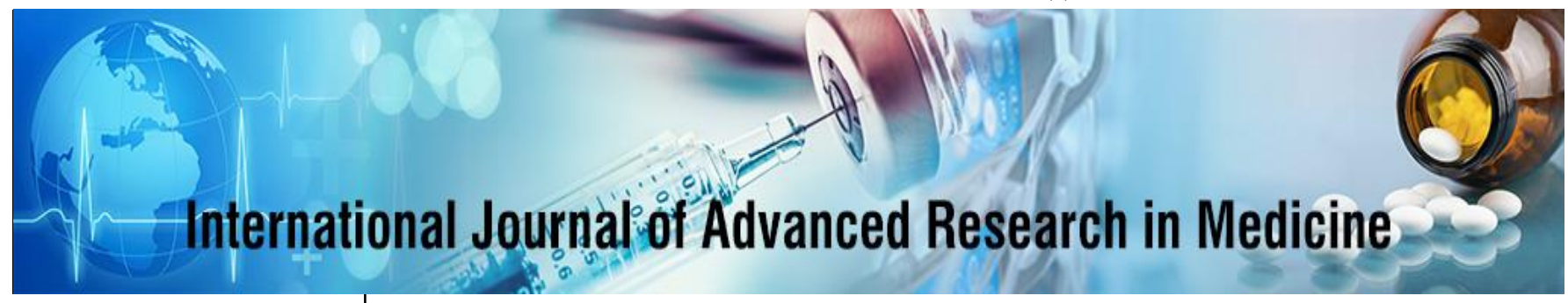

E-ISSN: 2706-9575 P-ISSN: 2706-9567

IJARM 2021; 3(1): 321-322

Received: 17-12-2020

Accepted: 22-01-2021

Dr. Anand KSS

Associate Professor,

Department of Physiology,

AIMS, B G Nagara,

Karnataka, India

\section{Model based teaching vs animation teaching in physiology}

\section{Dr. Anand KSS}

DOI: $\underline{\text { https://doi.org/10.22271/27069567.2021.v3.i1f.157 }}$

\begin{abstract}
Neuro-physiology has been one tough subject in terms of teaching and also learning. Students will not be able to understand it in 2 dimensional teaching which was practised from times unknown. The old tested method which included chalk and board was time tested but the orientation was very difficult as it was very difficult to understand 3 Dimensional structures. The tracts although considered simple, are a herculean task to remember. Adding to this, the old curriculum prescribes theory classes. So if the teacher is interested in explaining the topic practically, it is all the more exhausting to find good quality specimen. This study, although at nascent stage is a sincere attempt to find if the Model based teaching or the animation based teaching is superior in terms of students perfomance. Aims and objectives of the study is to understand and study the effectiveness of Model based teaching vs Animation teaching in Physiology.
\end{abstract}

Results: Better performance was seen in students who underwent Model based teaching.

Conclusion: Animation based can only be used in addition to the model based teaching. It is better for theory oriented approach.

Keywords: Model, Teaching, Animation, MCQ score

\section{Introduction}

Traditionally teaching CNS tract Physiology has been done using chalk and board. From our past experience at AIMS, B G Nagara it was found that teaching CNS tract physiology for MBBS 1st year students is often boring and monotonous. It is also found that students also pay less attention for the same. Medical Education is becoming more and more challenging as we get less number of faculties to teach. Even if it is available it is probably high-time to understand that over burden and personal problems affect teaching in Medical Colleges. It is also understood that the study of Physiology is slowly shifting from traditional teaching to studying Anatomy in live Humans. Many of the students also find it difficult to reproduce. It is a well-known fact that doing an activity by reading and understanding a subject will always be beneficial on a long basis. One more thing that has to be understood is the shortage of time for training the first year students, so more of interactive sessions should be incorporated in the system. Many authors have attempted this technique and have been successful in making this effort an enjoyable and memorable sessions. This study puts in an effort to understand the student's performance and thus we try to understand the superior method of teaching.

\section{Aims and Objectives}

To study the effectiveness of Model based teaching vs Animation teaching in Physiology.

\section{Materials and Methods}

This study was done in the Department of Physiology, AIMS, B.G. Nagara.

The study was done from Feb 2019 to March 2020.

The study was done in 100 students.

They were divided into 2 batches. One group was taught using Model based teaching and the other group was taught using Animation.

\section{Inclusion Criteria}

The first MBBS
Dr. Anand KSS

Associate Professor,

Department of Physiology,

AIMS, B G Nagara,

Karnataka, India 


\section{Exclusion criteria}

Students who did not consent.

The students were taught 3 sessions and at the end MCQ exams were conducted. Based upon the MCQ scores, the better performing group is assessed.

\section{Statistical Analysis}

Mann Whitney U test was done.

At the end of the study, the cross - over of the students was done for ethical reasons. But the scores were not considered for the study.

\section{Results}

Table 1: MCQ Results

\begin{tabular}{|c|c|c|c|c|c|}
\hline & \multicolumn{2}{|c|}{ Animation } & \multicolumn{2}{c|}{ Model based } & \multirow{2}{*}{ Mean value } \\
\hline & $\begin{array}{c}\text { Mtandard } \\
\text { Deviation }\end{array}$ & Mean & $\begin{array}{l}\text { Standard } \\
\text { Deviation }\end{array}$ & \\
\hline MCQ & 5.97 & 2.2 & 8.78 & 1.07 & $\leq 0.001$ \\
\hline MCQ-AFTER & 3.88 & 1.6 & 7.06 & 1.62 & $\leq 0.001$ \\
\hline MCQ DIFFERENCE & 2.09 & 2.6 & 1.72 & 1.75 & 0.572 \\
\hline
\end{tabular}

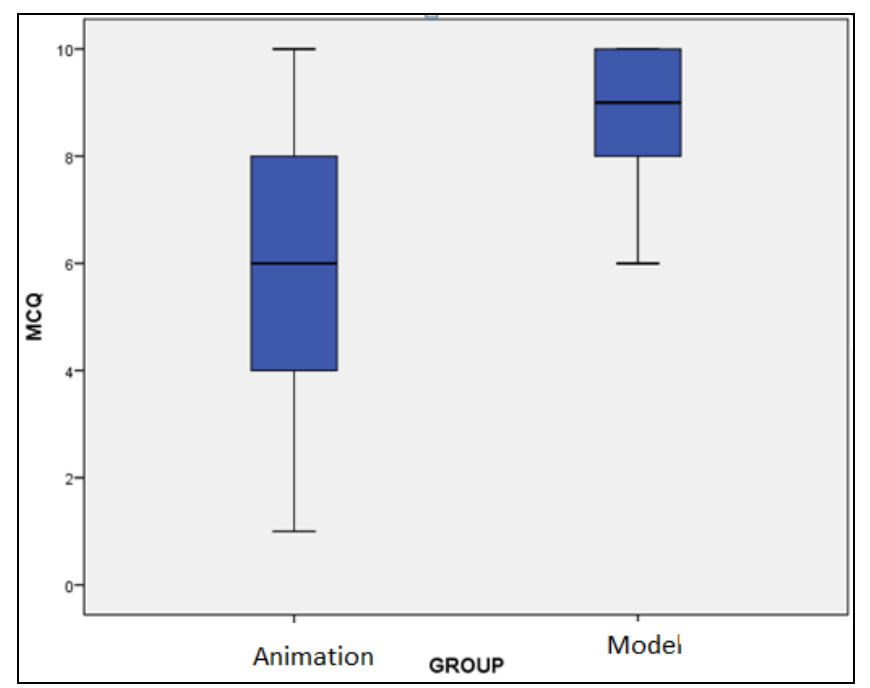

Graph 1: MCQ Results

\section{Discussion}

Often after first year the knowledge of an undergraduate is somewhat dwindled ${ }^{[1]}$. According to a study post first year, considerable loss of subject knowledge has been documented [2], In another study, surgery postgraduates were unable to identify the surgical planes in the initial period after joining ${ }^{[3]}$. So the teaching methodology should be such that the subject is remembered for a life-time by the students ${ }^{[4]}$. Teaching syllabus for 1 st year MBBS has been reduced to just ten months. Innovative teaching has become the need of the hour. Physiology has always been more of practical subject and with lack of time; lectures have become a main stray of teaching. Lectures are preferred as larger groups can be covered and save valuable time but the question always remains of whether it is effective. There are some topics in Physiology where practical approach is a must ${ }^{[5,6]}$. One such area is the Neuro-Physiology especially the tracts. It is a known fact that, in any subject if continuity is maintained then it becomes easier to teach the students. But in a subject like tracts in neuro-physiology, it becomes very difficult for the teachers and students to keep up with continuity as it is not easily visualised. Also teaching neurophysiology has been compartmentalised, so this study puts in a sincere effort to make a continuous visualisation to teach 1st year MBBS students effectively by using basic materials that is commonly available. So goal of teaching should be to create an environment to learn effectively ${ }^{[7]}$. As shown by the results, this innovative technique of teaching CNS tracts by using models made significant effect on medical students. Previously also different learning aids were used and updated to enhance student learning. Though learning is individual, the learning aids help to evoke student interest. E. Rathenberg has pointed out that teaching aids can make teaching interesting by reproducing reality in situations where exposure to actual reality is not possible or still premature ${ }^{[8]}$

\section{Conclusion}

The brain model method was superior when compared to the animation method. The scores were better and also the retainment of the subject was better.

\section{References}

1. Richardson DR. Comparison of naïve and experienced students of elementary physiology on performance in an advanced course. Adv Physiol Edu. 2000;23(1):9195.

2. D'Eon MF. Knowledge loss of medical students on first year basic science courses at the University of Saskatchewan. BMC Medical Education. 2006;6:5.

3. Mattar SG, Alseidi AL, Jones DB, Jeyarajah DR, Swanstrom LL, Aye RW et al. General surgery residency inadequately prepares trainees for fellowship: Results of a survey of fellowship program directors. Annals of Surgery. 2013;258(3):440-9.

4. DiCarlo SE. Too much content, not enough thinking, and too little FUN!. Adv Physiol Educ. 2009;33(4):25764.

5. Carvalho H. A group dynamic activity for learning the cardiac cycle and action potential. Advan Physiol Edu. 2011;35(3):312-3.

6. Krontiris-Litowitz J. Using manipulatives to improve learning in the undergraduate neurophysiology curriculum. Adv Physiol Educ. 2003;27(1-4):109-19

7. Saleem Ahmed, Helena Carvalho. The art of demonstration in anatomy instruction. Revista HUPE, Rio de Janeiro, 2014;13(4):46-51

8. Rathenberg E, Mielck A. Teaching aids used in professional education. How Does One Develop Teaching Aids for Professional Education? DSE (Deutsche Stiftung für internationale Entwicklung), 1992.

http://www.giz.de/Themen/en/dokumente/enpedagogyhow-does-one-develop-teaching-aids.pdf accessed at 2200hrs 18052013 